\title{
ISSR MARKERS FOR DETERMINATION OF GENETIC DIVERSITY IN SPILANTHES SPECIES - MEDICINAL HERB FROM PENINSULAR INDIA
}

\author{
${ }^{1 \& 2}$ Lavanya Devi K., ${ }^{1}$ Anuradha Sane and ${ }^{2}$ M.B. Shivanna \\ ${ }^{1}$ Division of Plant Genetic Resources, Indian Institute of Horticultural Research, Bengaluru, Karnataka, \\ India- 560089 \\ ${ }^{2}$ Department of Applied Botany, Kuvempu University, Jnana Sahyadri, Shankaraghatta, Shivamogga, \\ Karnataka, India- 577451.
}

*Corresponding Author Email: lavanyakotekar@gmail.com

\begin{abstract}
Inter-simple sequence repeat (ISSR) analysis was carried out to determine the genetic diversity of six species of Spilanthes in peninsular India. Eighteen primers with good banding pattern were selected for the study based on their reproducibility. The results of PCR based ISSR analysis revealed 96.51\% polymorphism and 0.19 to 0.35 polymorphic information content. The marker index (4.57 to 8.63) and observed heterozygosity $\left(H_{0}\right)(0.2, U B C 854)$ to $(0.54, U B C 856)$ with an average of 0.36 , expected heterozygosity $\left(H_{e}\right)(0.18$ UBC 854 to 0.35 UBC 853) with an average of 0.26 were documented for all Spilanthes accessions. The Shannon's diversity index ranged from 0.84 (UBC 857) to 1.46 (UBC 853). The average resolving power was 19.87 per ISSR primer. The highest RP value of 25.69 was observed with ISSR primer UBC 836 and the lowest of 15.96 with UBC 873. The phylogenetic analysis indicated that individuals were morphologically distinct species and formed individual clusters. The principal coordinate analysis indicated correlation with similarities and the geographic distances among the species. The Mantel test proved the correlation of molecular matrix with morphological and geographic distance matrix among the accessions. The prevalence of diversity in Spilanthes species in peninsular India is demonstrated for the first time using ISSR markers.
\end{abstract} KEY WORDS

Spilanthes, ISSR, PIC, phylogeny, Mantel test.

\section{INTRODUCTION}

Spilanthes Jacq. ( spp. Family: Asteraceae, tribe: Heliantheae) is a specious group distributed both in the New and Old World tropics, as well. Amongst six species of Spilanthes viz., S. paniculata Wallich ex DC. and S. calva (DC.) R.K. Jansen are native to India, while, S. uliginosa (Swartz) Cassini, S. ciliata (Kunth) Cassini and S. radicans (Jacquin) R.K. Jansen. are immigrant species (Shivarajan and Mathew, 1984). S. oleracea Linnaeus R.K. Jansen, a cultivated species introduced from Brazil (Hooker, 1872). Ray headed species include S. calva, S. ciliata, S. paniculata. and S. uliginosa, while the discoid headed include $S$. oleracea and S. radicans. Most of the species find importance in traditional medicines and alkamides extracted from them are effective in curing toothache and throat infections; it is also used as local anesthetic and digestive tonic (Ramsewak et al. 1999). It is reported to possess anti-inflammatory, antiseptic, analgesic, antioxidant and cytotoxic properties (Jondiko et al. 1986; Saritha et al. 2002; Rai et al. 2004; Wu et al. 2008; Prachayasittikul et al. 2009).

The molecular markers have been used in various activities like plant breeding, conservation of genetic resources, disease resistance, gene mapping, linkage studies and genetic diversity studies. The most common markers involved are random amplified polymorphic DNA (RAPD, Welsh and McClelland, 
1990; Williams et al. 1990), amplified fragment length polymorphism (AFLP, Vos et al. 1995), restriction fragment length polymorphism (RFLP, Botstein et al. 1980), diversity array technology (DART, Wenzl et al. 2004), sequence-tagged sites (STS, Bradshaw et al. 1994), single nucleotide polymorphism (SNP, Wang et al. 1998), single simple repeat (SSR, Tautz, 1989; Weber and May, 1989), and inter-simple single repeat (ISSR, Zietkiewicz et al. 1994). The ISSR markers were developed from the need to explore microsatellite repeats without prior knowledge of DNA sequences (Lagercrantz et al. 1993). The technique is based on the amplification of DNA segments between two microsatellite repeated regions (Zietkiewicz et al. 1994). Hence, the ISSR is a simple, quick and an efficient technique that produces amplified products in the range of 2002000 base pairs. The ISSR marker (dominant) system is based on the use of 15-20 bp primers which are complimentary to SSR (microsatellite) sequences found throughout the eukaryotic genomes. The microsatellite repeats target multiple genomic loci to amplify their ISSR sequences of different sizes. In addition, this could be used to confirm the presence and evaluate the distribution of certain microsatellite repeats within the genome (Zietkiewicz et al. 1994). This is useful in identifying individual specific differences, inter-species genomic finger-printing, genetic diversity, phylogenetic inferences, gene tagging, genome mapping and evolutionary biology (Godwin et al. 1997; Reddy et al. 2002; Panda et al. 2003; Bornet and Branchard, 2004; Zhang et al. 2013). The ISSR markers are widely applied in taxonomic studies due to high variation of banding sequences at the population and interspecific level (Vanderpoorten et al. 2003; Dogan et al. 2007) as well as in studies investigating genetic diversity at the species level (Gunnarsson et al. 2005; Liu et al. 2007; Szczecinska et al. 2009). Although morphological variations in Spilanthes species are documented, there is no molecular evidence on genetic diversity of these species. In the present study, the molecular characterization of Spilanthes species was attempted by using ISSR markers to determine the inter-specific and intra-specific variations occurring in Spilanthes distributed in the peninsular India and correlation among molecular, morphological and geographical distance of the accessions.

\section{MATERIALS AND METHODS}

\section{Collection of plant material}

In the present study, six species of Spilanthes viz., $S$. calva, S. ciliata, S. oleracea, S. paniculata, S. radicans and $S$. uliginosa occurring in the peninsular India were selected for their characterization by using the ISSR technique. Plants collected from various locations (Fig.1). were grown in a shade house at Field Gene Bank of Division of Plant Genetic Resources, Indian Institute of Horticultural Research (IIHR), Bangalore, India. Details of collection locations from peninsular India are detailed in Table A1(supplementary material).

\section{Protocol for optimization of plant DNA isolation and} PCR-ISSR analysis

The genomic DNA was extracted principally by the Cetyl trimethyl ammonium bromide (CTAB) method (Doyle and Doyle, 1987). The plant parts exhibited the presence of phenols that interfered in obtaining pure DNA sample, hence modified CTAB method was employed to obtain clear creamish DNA. The purity checking was carried out using the UV spectrophotometer where the optical density ratio was optimum (OD260:280 around 1.8-2.0). The gel electrophoresis also exhibited clear DNA bands. A preliminary optimization of DNA isolation and 7-8 PCR ISSR analyses showed that the amplification could be carried out as described previously (Lavanya et al. 2014). In this study, 75 ISSR primers from University of British Columbia (UBC) were screened initially and 18 primers that yielded amplification products for all six species were selected for PCR ISSR analysis. The details of the primers and sequences are detailed in Table A2 (supplementary material).

\section{Characteristics of amplified bands from ISSR markers}

Each ISSR band was identified as an independent locus and distinct, reproducible bands were considered for scoring. The scoring was carried out manually by observing for the presence of ISSR bands (presence $=1$ or absence $=0$ ) to determine polymorphism in each locus. The amplified product of each primer was determined for the total number of amplified bands; number of polymorphic bands (bands not amplified in all accessions) and number of monomorphic bands (bands present in all 
accessions), maximum number of bands, minimum number of bands and average bands.

\section{Analysis of ISSR markers}

In order to determine the suitability of ISSR markers for evaluation of genetic profiles, the performance of markers was measured using parameters such as percentage polymorphism (PP), polymorphic information content (PIC), Nei's genetic distance, observed heterozygosity (Ho), expected heterozygosity $(\mathrm{He})$, marker index (MI), resolving power (RP) and principal coordinate analysis (PCA). The PIC refers to the value of a marker for detecting polymorphism within a population. The PIC depended on the number of detectable alleles and the distribution of their frequency (Boostein et al., 1980, Anderson et al. 1993). Hence, the PIC of each primer was calculated using the average PIC value from all loci of each primer. The MI was calculated as described (Varshney et al. 2005).

$\mathrm{MI}=\mathrm{EMR} \times \mathrm{PIC}$

Effective multiplex ratio $(E M R)=n \times \beta$

where $n$ is the average number of bands amplified by accession to a specific system marker (multiplex ratio) and $\beta$ is estimated from the number of polymorphic loci ( $\mathrm{np}$ ).

The number of non-polymorphic loci (nnp), $\beta=n p /$ $(n p+n n p)$.

The RP of each primer was calculated (Prevost and Wilkinson, 1999) as- RP $=\Sigma \mathrm{lb}$

where $\mathrm{lb}$ represents the informative fragments. The Ib can be represented on a scale of $0-1$ by the following formula: $\mathrm{lb}=1-(2 \times(0.5-\mathrm{p}))$

where $p$ is the proportion of accessions containing the band.

The genetic diversity of ISSR marker was evaluated by calculating Shannon diversity Index

Shannon diversity index (H) was calculated (Lewontin, 1972) as- $\mathrm{H}=\Sigma$ pilog2pi

where $\mathrm{pi}$ is the frequency of a given band for each population.

To find the relationship between genetic composition and geographic distribution of accessions, genetic composition and morphological data matrix and all the three were tested for correlation using the partial Mantel test (Mantel
1967; Mantel and Valand 1970). The Euclidean distance matrix (D) was computed and converted to a similarity(S) matrix by formula $S=1$ - D. A Nei's genetic similarity matrix (Nei and Li, 1979) was also computed for the genetic data. Using the geographical coordinates of the collection localities, a geographic distance matrix was computed and converted into a similarity matrix. All matrices were tested for pair-wise correlation $(p<0.05)$, using Mantel's non-parametric test (Mantel, 1967).

The principal coordinate analysis (PCO) was performed. The Nei's genetic distance matrix was subjected to phylogenetic analysis (Parsimony method, Paup Verison 4.0) to assess genetic relationships among accessions. All above statistical analyses were determined by the program NTSYS-pc 2.11.

\section{RESULTS AND DISCUSSION}

\section{ISSR scoring and data analysis}

The selected primers (18) generated a total of 2215 bands from 30 accessions, amongst which 2137 bands were polymorphic (96.50\%). The maximum amplification was observed due to primer 855 (163 fragments) and minimum observed due to primer 844 (38 fragments). Each primer caused various levels of polymorphism to differentiate the species and $100 \%$ polymorphism was observed in primersUBC 841, 842, 844, 845, 846, 847, 852, 853, 854, 855, 858,860 and 866 (Table 1). The band length ranged from 134 to 1100 . The fragment numbers were 3476 for 844,854 and $857 ; 78-120$ for 860,866 and 858 ; $121-140$ fragments for $843,845,842$ and $852 ; 141$ 165 fragments for $841,853,846,847,856,840$ and 855 (Figure 1). The results indicated that ISSR markers could be used effectively to analyze the genetic diversity in Spilanthes. Although species of Spilanthes viz., S. calva, S. ciliata, S. oleracea, S. paniculata, S. radicans and S. uliginosa in peninsular India could be identified morphologically (Lavanya et al. in press), there is a published report analysis of genetic diversity of Chrysanthemum varieties at the varietal and species levels, which was determined successfully by ISSR markers (Arup et al. 2013). 


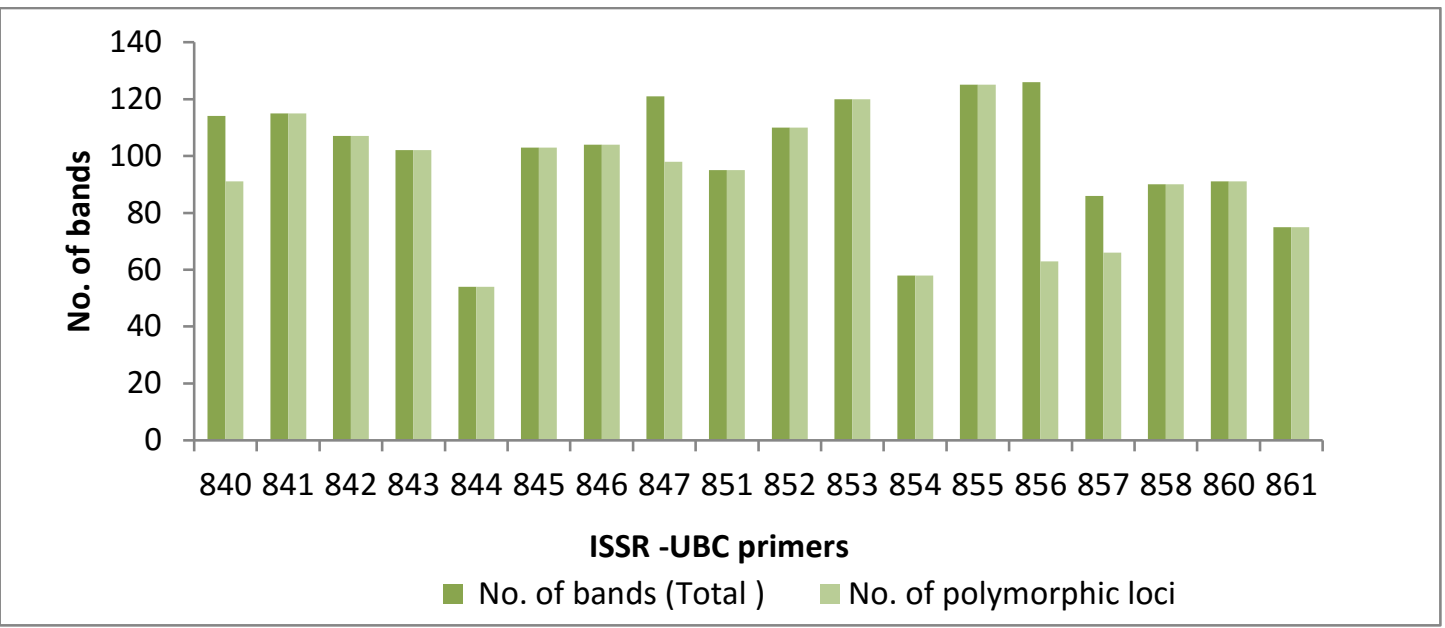

Figure 1: The number of bands and polymorphic loci yielded for 30 accessions of Spilanthes spp. using UBC ISSR primers.

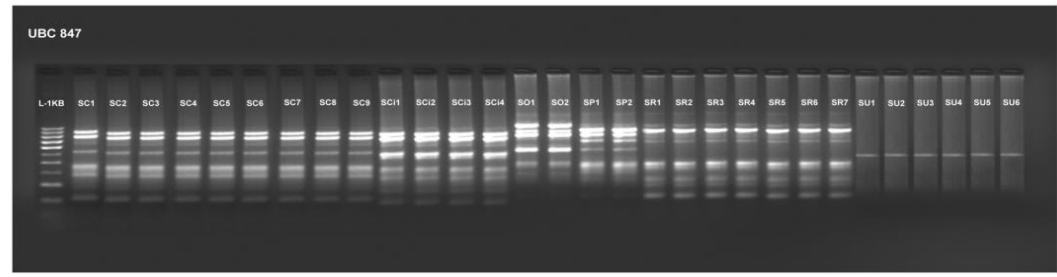

Figure 2: ISSR finger-prints generated using primer UBC 856 from 30 accessions of Spilanthes collected from peninsular India

Table 1: Amplified products of UBC ISSR markers and their characteristics

\begin{tabular}{|l|l|l|l|l|l|l|l|}
\hline SN & UBC ISSR Primer & TNB & NPB & PP & MXNB & MNNB & AVG B \\
\hline 1. & 840 & 9 & 8 & 88.88 & 9 & 2 & 4.95 \\
\hline 2. & 841 & 9 & 9 & 100 & 8 & 2 & 5 \\
\hline 3. & 842 & 9 & 9 & 100 & 7 & 1 & 4.6 \\
\hline 4. & 843 & 8 & 7 & 87.5 & 6 & 1 & 4.43 \\
\hline 5. & 844 & 7 & 7 & 100 & 4 & 1 & 2.34 \\
\hline 6. & 845 & 9 & 9 & 100 & 9 & 1 & 4.47 \\
\hline 7. & 846 & 8 & 8 & 100 & 8 & 1 & 4.42 \\
\hline 8. & 847 & 10 & 9 & 100 & 8 & 5 & 4.26 \\
\hline 9. & 851 & 8 & 7 & 87.5 & 6 & 3 & 4.13 \\
\hline 10. & 852 & 11 & 11 & 100 & 8 & 1 & 4.78 \\
\hline 11. & 853 & 11 & 9 & 100 & 8 & 2 & 5.21 \\
\hline 12. & 854 & 9 & 9 & 100 & 8 & 2 & 2.52 \\
\hline 13. & 855 & 9 & 9 & 100 & 7 & 4 & 5.43 \\
\hline 14. & 856 & 8 & 7 & 87.5 & 8 & 4 & 2.73 \\
\hline 15. & 857 & 7 & 6 & 85.7 & 5 & 1 & 2.86 \\
\hline 16. & 858 & 8 & 8 & 100 & 6 & 3 & 3.91 \\
\hline 17. & 860 & 9 & 9 & 100 & 8 & 2 & 3.95 \\
\hline 18. & 866 & 10 & 10 & 100 & 10 & 2 & 3.26 \\
\hline
\end{tabular}


Data screening is based on $\mathbf{3 0}$ accessions of Spilanthes collected from peninsular India.

$\mathrm{TNB}=$ total number of bands; $\mathrm{NPB}=$ number of polymorphic bands; $\mathrm{PP}=$ percentage polymorphism; $\mathrm{MXNB}=$ maximum number of bands; $\mathrm{MMNB}=$ minimum number of bands; $\mathrm{AVGB}$ - average number of bands per primer).

Table 2: Genetic diversity of Spilanthes accessions and parameters studied using 18 UBC ISSR primers.

\begin{tabular}{llllllllll}
\hline SI. No. & UBC ISSR Primer & Ho & He & FR & DI & MI & PIC & RP & SDI \\
\hline 1. & 840 & 0.46 & 0.29 & 0.91 & 0.73 & 7.33 & 0.26 & 5.4 & 1.16 \\
2. & 841 & 0.39 & 0.28 & 1 & 0.65 & 6.53 & 0.24 & 5.13 & 1.21 \\
3. & 842 & 0.37 & 0.28 & 1 & 0.64 & 7.07 & 0.27 & 5.6 & 1.23 \\
4. & 843 & 0.37 & 0.21 & 0.91 & 0.77 & 8.47 & 0.20 & 3.8 & 0.88 \\
5. & 844 & 0.22 & 0.19 & 1 & 0.55 & 6 & 0.15 & 4.47 & 0.92 \\
6. & 845 & 0.38 & 0.29 & 1 & 0.46 & 4.57 & 0.30 & 7.67 & 1.41 \\
7. & 846 & 0.38 & 0.29 & 1 & 0.8 & 9.6 & 0.27 & 6.47 & 1.23 \\
8. & 847 & 0.41 & 0.33 & 1 & 0.56 & 6.2 & 0.30 & 7.93 & 1.53 \\
9. & 851 & 0.37 & 0.26 & 1 & 0.59 & 6.5 & 0.24 & 4.2 & 1.02 \\
10. & 852 & 0.41 & 0.33 & 1 & 0.63 & 6.97 & 0.30 & 7 & 1.4 \\
11. & 853 & 0.44 & 0.35 & 1 & 0.59 & 7.03 & 0.33 & 7.47 & 1.46 \\
12. & 854 & 0.2 & 0.18 & 1 & 0.62 & 6.83 & 0.16 & 4.8 & 1.06 \\
13. & 855 & 0.54 & 0.29 & 1 & 0.62 & 6.83 & 0.27 & 2.33 & 0.87 \\
14. & 856 & 0.45 & 0.32 & 1 & 0.78 & 8.63 & 0.30 & 5.6 & 1.19 \\
15. & 857 & 0.23 & 0.18 & 1 & 0.63 & 5.7 & 0.15 & 3.6 & 0.84 \\
16. & 858 & 0.36 & 0.27 & 1 & 0.63 & 7.6 & 0.25 & 5.2 & 1.1 \\
17. & 860 & 0.35 & 0.23 & 0.92 & 0.61 & 7.3 & 0.21 & 6.07 & 1.19 \\
18. & 861 & 0.27 & 0.24 & 1 & 0.54 & 4.88 & 0.22 & 5.33 & 1.1 \\
\hline & & & & & & & & &
\end{tabular}

Data screening is based on $\mathbf{3 0}$ accessions of Spilanthes collected from peninsular India.

Ho=observed heterozygosity; He=expected heterozygosity; $\mathrm{Fr}=$ frequency of polymorphic bands; $\mathrm{DI}=$ diversity index; $\mathrm{MI}=$ =marker index; $\mathrm{PIC}=$ =olymorphic information content; $\mathrm{RP}=$ resolving power; SDI=Shannon diversity index for 18 UBC ISSR primers.

The PIC analysis was carried out to determine the efficiency of each ISSR marker to express polymorphic loci in Spilanthes. The calculated PIC values for ISSR markers ranged from 0.15 to 0.33 . The highest mean PIC value of 0.33 expressed by primer UBC 853 indicated that this primer was the most polymorphic. The primer UBC 857, which yielded the lowest mean PIC value of 0.15 , was the least polymorphic. The MI ranged from 4.57 for UBC 845 to 8.63 for UBC 856 which indicated that the latter primer was the most efficient in detecting polymorphism.

As far as the genetic diversity parameters are concerned, observed heterozygosity $(\mathrm{Ho})$ ranged from 0.2 (UBC 854) to 0.54 (UBC 856) with an average of 0.36 , whereas the expected heterozygosity $(\mathrm{He}$, genetic diversity) ranged from 0.18 (UBC 854) to 0.35 (UBC 853) with an average of 0.26 for Spilanthes accessions. The Shannon diversity indices (SDI) ranged from 0.84 (UBC 857) to 1.46 (UBC 853). The resolving power (RP) is a parameter that indicated the discriminatory potential of primers chosen. While the average RP was 19.87 per ISSR primer, the highest RP value was observed with the ISSR primer 836 (25.69) and the lowest with the ISSR primer 873 (15.96) (Table 2).

Polymorphism in a given population occurs due to the existence of genetic variants which is represented by the number of alleles at a locus and their frequency of distribution in a population. In the present study, the percentage of polymorphism due to UBC ISSR markers was high as revealed by the 
differentiation of species. There are several comparative studies with RAPD showing high polymorphism than the ISSR (Shaffie et al. 2011).

The technique of ISSR has been successful in determining the difference among polyploids and diploids (Reddy et al. 2002). The individual polyploids have resulted following hybridization. The genus Spilanthes is self-pollinated but random crossing could have resulted in the formation of hybrids (Jansen, 1980). The change in morphological characteristics such as radiate to discoid heads and the reduction in the number of floral parts support the possibility of hybridization of self-pollinated randomly crossing species of Spilanthes on opined by Jansen (1980). The ISSR markers could be employed for these investigation to differentiate the taxa status at species and varietal level.

The Mantel test for ISSR data matrix with geographical data for collection locations of species, ISSR similarity matrix and morphological similarity matrix (Lavanya et al. 2014 in press) indicated a positive correlation. Correlation of three matrices by partial Mantel test was positive as well, indicating the good correlation among three data sets.

Correlation test conducted for each morphological character with each primer and vice-versa and with geographic distance of accessions with the genetic similarity matrix and vice-versa. Among morphological characters' flower head diameter and leaf lamina length exhibited good correlation ( $r=0.3673$ and $r=0.2103)$. The morphological characters like stipule size, leaf lamina width, peduncle length exhibited moderate correlation, but it was not significant ( $p>0.05$ ). Whereas correlation of each primer with morphological similarity matrix when performed, exhibited high correlation for UBC 840 and low for 861 ( $r=0.6928$ and $r=0.2774)$, correlation value $(r>0.6)$ was achieved for UBC 840 , $842,847,851$ and 860 . The correlation values $(r<0.3)$ achieved for UBC 854 and 861 and all values were significant ( $p<0.05)$. The partial Mantel test correlated for three similarity matrices, a positive correlation ( $r=0.648)$ was achieved and was significant $(p=0.002)$. The correlation among the genetic and geographical distances showed $r=0.2207$ with $p$ value of 0.4404 ; on the other hand, the genetic similarity matrix with morphological similarity matrix correlation was positive $(r=0.6455$ and $\mathrm{p}=0.001$ ).

Principal coordinate analysis (PCA) The related species were clearly separated by principal coordinate analysis (PCA). The grouping of samples in principal coordinate analysis was according to the morphological grouping of species of Spilanthes and accessions were segregated within the genus according to geographical variations and similarities within the species (Fig 3).

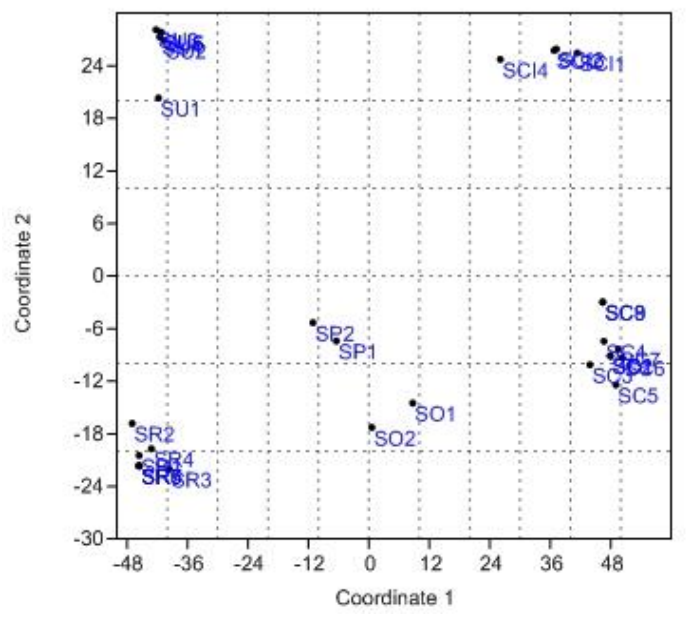

Figure 3. Two-dimensional representation of principal coordinate analysis of genetic relationships of Spilanthes spp. inferred from similarity matrix using the Jaccard's index by UBC ISSR markers. S. calva:SC1-SC9, S. ciliata: SCI1-SCI4, S. oleracea: SO1, SO2, S. paniculata: SP1, SP2, S. radicans:SR1-SR7, S. uliginosa: SU1-SU6.

\section{Cluster analysis}

Based on the genetic distances, the phylogenetic tree was constructed to determine the relation of Spilanthes accessions at the interspecific, intraspecific levels and within the species of Spilanthes accessions. The species were differentiated clearly in the tree, with each species forming an individual subcluster. Accordingly, species $S$. uliginosa and $S$. radicans were closely related, while S. paniculata was closely related to this sub-cluster, whereas $S$. oleracea and S. paniculata were clustered together. The cluster of $S$. oleracea, $S$. paniculata and $S$. radicans and the cluster of S. calva and S. ciliata were connected to third sub-cluster. Two accessions of $S$. calva were separated from the species individual cluster. The clusters clearly differentiated the species and within the species the distance among 
accessions were correlated to the geographical distances. The correlation between the genetic data and geographical distances and correlation with morphological similarity matrix and all three revealed by the Mantel test, was confirmed by the PCO analysis (Fig 3 ) and clearly so by the Parsimony dendrogram (Fig 4).

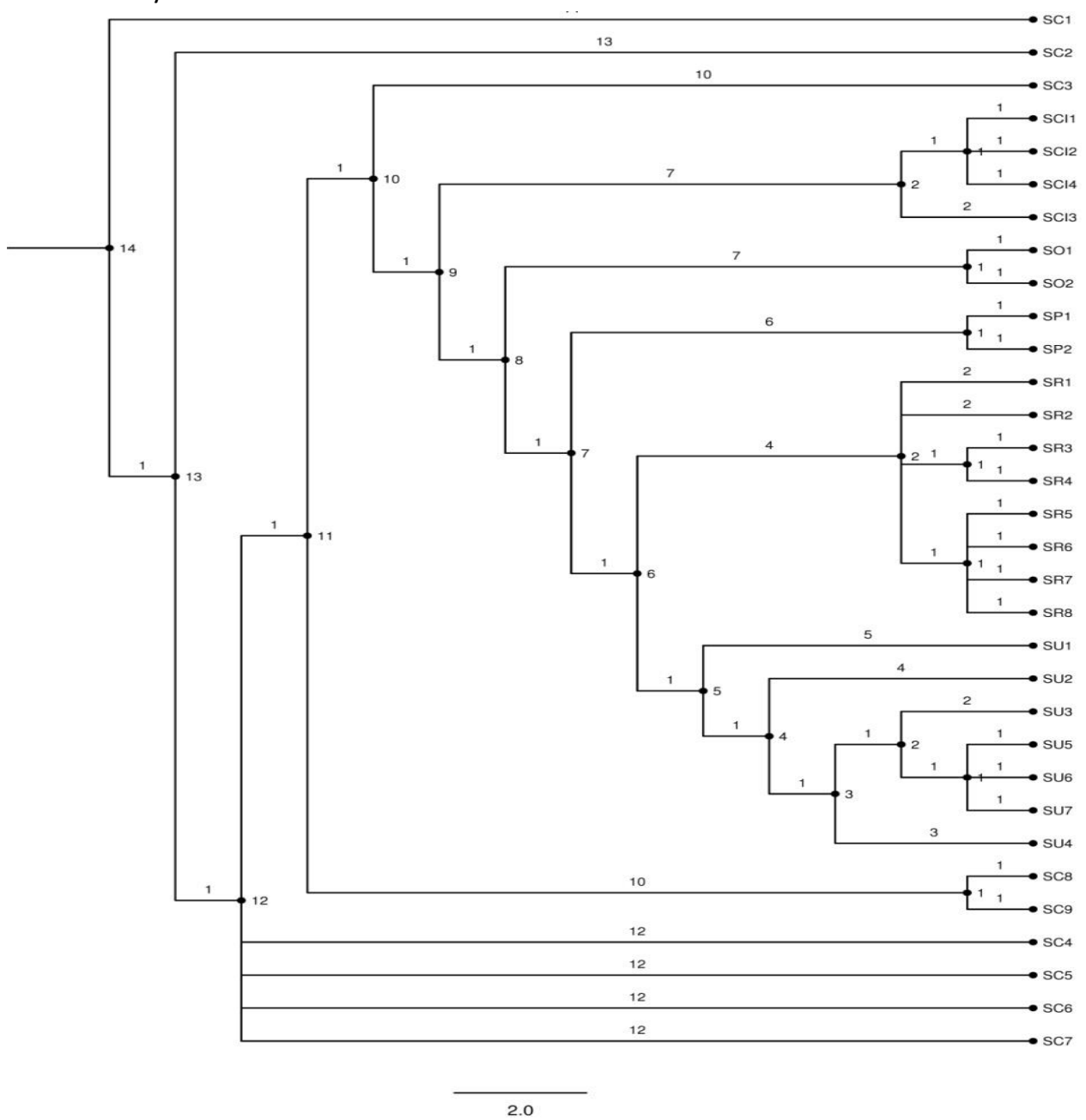

Figure 4. Phylogeny of Spilanthes accessions generated by PAUP on the similarity matrix obtained using Nei's genetic distance based on ISSR data (Nei, 1978).

\section{CONCLUSION}

In the present study the markers were technique of ISSR used for successful differentiation the species of Spilanthes occurring in peninsular India. Further the existence of polyploids and their relationship with diploid individuals during the course of evolution could be studied. The genus Spilanthes is known to be closely related to genus Acmella (Richard, 1807) and is characterized by the presence of discoid heads and pappus of awns. Taxonomic studies by Cassini in 1822 that focused on the characterization of two genera Spilanthes and Acmella concluded that Acmella differs from Spilanthes only in having radiate heads and hence these two genera cannot be separated reliably by differences of the pappus. Since then, this genus has been traditionally divided into two sections, Spilanthes and Acmella Rich (Candolle 1836; Moore 1907). More recently morphological and chromosomal studies suggest that Acmella and Spilanthes should be considered as two distinct genera and the features used to separate the taxa are described as follows (Jansen 1980; 1985). In this context a detailed study of both the taxa Spilanthes and Acmella is need of the hour. The species distributed in Peninsular India morphologically are in accordance with the Acmella species described by Jansen $(1981,1985)$. In this context, the molecular study (ISSR) of these species is a foundation for 
studies of these taxa and their revision in Peninsular India.

\section{ACKNOWLEDGEMENT}

The authors sincerely thank The Director, Indian Institute of Horticultural Research Bangalore, Karnataka, India for providing facilities for carrying out the present research. The authors sincerely thank all those who helped in the field collections.

\section{REFERENCES}

1. Anderson JA, Churchill GA, Autrique JE, Tanksley S, Sorrells ME (1993). Optimizing parental selection for genetic linkage maps. Genome. 36:181-186

2. Angeles JGC, Laurena AC, Mendoza EMT (2005). Extraction of genomic DNA from the lipid, polysaccharide and polyphenol rich coconut (Cocos nucifera L.). Plant Mol. Biol. Rep 23:297298.

3. Arup KM, Atanu D, Laxmikant A, Siddhartha KP, Prathap CP (2013). Studies on genetic diversity in elite varieties of Chrysanthemum using RAPD and ISSR markers. Indian Journal of Biotechnology. 12:161-169.

4. Bornet B, Branchard M (2004). Use of ISSR fingerprints to detect microsatellites and genetic diversity in several related Brassica taxa and Arabidopsis thaliana. Hereditas 140:246-248. DOI:10.1111/j.1601-5223.2004.01737.

5. Botstein $D$, White RL, Skolnick $M$, Davis RW (1980). Construction of a genetic linkage map in man using restriction fragment length polymorphisms. Am. J. Hum. Genet. 32:314331.

6. Bradshaw HDJ, Villar M, Watson BD, Otto KG, Stewart S (1994). Molecular genetics of growth and development in Populus. III. A genetic linkage map of a hybrid poplar composed of RFLP, STS and RAPD markers. Theor. Appl. Gene. 89:167-178.

7. Dogan B, Duran A \& Hakki EE (2007) Phylogenetic analysis of Jurinea (Asteraceae) species from Turkey based on ISSR amplification. Ann. Bot. Fenn. 44:353-358.

8. Doyle JJ, Doyle JL (1990). Isolation of plant DNA from fresh tissue. Focus 12:13-15.

9. Geiduschek EP, Herskovits TT (1961). Non aqueous solutions of DNA. reversible and irreversible denaturation in methanol. Arch Biochem. Biophys. 95:114-129.
10. Godwin ID, Aitken EAB, Smith LW (1997). Application of Inter Simple Sequence Repeat (ISSR) markers to plant genetics. Electrophoresis 18:1524-1528. DOI: 10.1002/elps.1150180906.

11. Grant V, Plant speciation. 2nd edn. (1981) Columbia University Press, New York.

12. Gupta M, Chyi YS, Romero-Severson J, Owen JL (1994). Amplification of DNA markers from evolutionarily diverse genomes using single primers of simple-sequence repeats. Theor. Appl Genet. 89:998-1006.

13. Hundsdoerfer AK, Kitching IJ, Wink M (2005). The phylogeny of Hyles euphorbiae complex (Lepidoptera: Sphingidae): Molecular evidence for sequence data and ISSR-PCR fingerprints. Org. Divers Evol. 5:173-198. DOI: 10.1016/j.ode.2004.11.012.

14. Jansen R K, Systematics of Spilanthes (Compositae :Heliantheae) (1981). Syst. Bot. 6:231-257.

15. Jansen RK (1985) The systematics of Acmella (Asteraceae - Heliantheae). Syst. Bot. Monogr., 8: 1-115.

16. Jenny KA, Daniel J, Crawford, Arnoldo S, Mark EM (2006). The utility of automated analysis of InterSimple Sequence Repeat (ISSR) loci for resolving relationships in the Canary Island species of Tolpis (Asteraceae). Am. J. of Bot. 93:1154-1162.

17. Jondiko IJO (1986). A mosquito larvicide in Spilanthes mauritiana. Phytochemistry. 25:2289-2290

18. Joshi SP, Gupta VS, Agarwal RK, Ranjekar PK, Brar DS (2000). Genetic diversity and phylogenetic relationship as revealed by inter-simple sequence repeat (ISSR) polymorphism in the genus Oryza. Theor. Appl. Genet. 100:13111320.

19. Khare CP (2007). Indian medicinal plants: An illustrated dictionary. 621.

20. Kozyrenko MM, Gontcharova SB, Gontcharoy AA (2011). Analysis of the genetic structure of Rhodiola rosea (Crassulaceae) using inter-simple sequence repeat (ISSR) polymorphisms. Flora. 206:691-696.

21. Kunsiri C, Grubbs AE, Randall L, Small AE, Edward ES (2009). Evidence for multiple, autoploid origins of agamospermous populations in Eupatorium sessilifolium (Asteraceae). Plant Systematics and Evolution. 279:151-161. DOI 10.1007/s00606-009-0155-y.

22. Lagercrantz U, Ellegren $H$, Andersson $L$ (1993). The abundance of various polymorphic 
microsatellite motifs differs between plant and vertebrates. Nucleic Acids Res. 21:1111-1115.

23. Lavanya DK, Anuradha S, Shivanna MB, Ganeshan S (2014). Optimization of DNA isolation and PCR ISSR of species of Spilanthes from peninsular India. Inter. J. Sci. Res.3(9):10881091.

24. Lewontin RC (1972). The apportionment of human diversity. Evolutionary Biology. 6:381398.

25. Liu XQ, Grruru RW, Chen LQ (2007) Genetic variation in the endangered fern Adiantum reniformae var. sinensis (Adiantaceae) in China. Ann. Bot. Fenn. 44:25-32.

26. Nei M (1972). Genetic distance between populations. Am. Nat. 106:283-292.

27. Panda S, Martin JP, Aguinagalde I (2003). Chloroplast and nuclear DNA studies in a few members of the Brassica oleracea L. group using PCR-RFLP and ISSR-PCR markers: A population genetic analysis. Theor. Appl. Genet. 106:11221128. DOI: 10.1007/s00122-002-1134-7.

28. Pasakinskiene I, Griffiths CM, Bettany AJE, Paplauskiene V, Humphreys MW (2000). Anchored simple-sequence repeats as primers to generate species-specific DNA markers in Lolium and Festuca grasses. Theor. Appl. Genet. 100:384-390.

29. Powell W, Morgante $M$, Andre C, Hanafey M, Voges J, Tingey S, Rafalski A (1996). A comparison of RFLP, RAPD, AFLP and SSR (microsatellite) markers for germplasm analysis. Mol. Breed. 2: 225-230.

30. Prevost A, Wilkinson MJ (1999). A new system of comparing PCR primers applied to ISSR fingerprinting of potato cultivars. Theor. Appl. Gen. 98 107-112.

31. Qian W, Ge S, Hong DY (2001). Genetic variation within and among populations of a wild rice Oryza granulate from China detected by RAPD and ISSR. Theor. Appl. Genet. 102:440-449. DOI: 10.1007/s001220051665.

32. Rai MK, Varma A, Pandey AK (2004). Antifungal potential of Spilanthes calva after inoculation of Piriformospora indica. Mycoses. 47:479-481.

33. Ramsewak RS, Erickson AJ, Nair MG (1999). Bioactive $\mathrm{N}$ isobutylamides from the flower buds of Spilanthes acmella. Phytochemistry. 51:729732.

34. Reddy MP, Sarla N, Siddiq EA (2002). Inter Simple Sequence Repeat (ISSR) polymorphism and its application in plant breeding. Euphytica. 128:917. DOI: 10.1023/A:1020691618797.
35. Rees WA, Yager TD, Korte J, Hippel VPH (1993). Betaine can eliminate the base pair composition dependence of DNA melting. Biochemistry 32:137-44.

36. Salimath SS, de Oliveira AC, Godwin ID, Bennetzen JL (1995). Assessment of genome origins and genetic diversity in the genus Eleusine with DNA markers. Genome, 38:757-763.

37. Saritha KV, Prakash E, Ramamurthy MN (2002). Micropropagation

of Spilanthes acmella Murr. Biol. Plantarum. 45: 581-584.

38. Sczcecinska M, Sawicki J, Wasqwicz K, Holdynski CZ (2009). Genetic variation of the relict and endangered population of Chamaedaphne calyculata (Ericaceae) in Poland. Dendrobiology. 62:23-33.

39. Shafie M, Shafie B, Hasan SMZ, Abdullah MZ, Ramisah MS (2011). RAPD and ISSR markers for comparative analysis of genetic diversity in wormwood capillary (Artemisia capillaris) from Negeri Sembilan, Malaysia. Journal of Medicinal Plants Research. 5:4426-4437.

40. Shivarajan VV, Mathew P (1984). Notes on three immigrant species of Spilanthes Jacq. Asteraceae in India and the identity of the common "Toothache Plant". Anc. Sci. of Life. 3:169-73.

41. Stebbins (1980). Review of "Plant Evolution through amphiploidy and autopolyploidy. Ecology. 26: 420-421.

42. Tautz D (1989). Hypervariability of simple sequences as a general source of polymorphic DNA markers. Nucleic Acids Res, 17:64636471.

43. Tsumura Y, Ohba K, Strauss S (1996). Diversity and inheritance of inter-simple sequence repeat polymorphisms in Douglas-fir (Pseudotsuga menziesii) and sugi (Cryptomeria japonica). Theor. Appl. Genet. 92:40-45.

44. Vanderpoorten A, Hedenas L, Jacquemart AL (2003). Differentiation in DNA fingerprinting and morphology among species of Pleurocarpus moss genus, Rhytidiadelphus (Hylocomiaceae). Taxon. 52:229-236.

45. Varshney RK, Graner A, Sorrells ME (2005). Genic microsatellite markers in plants: features and applications. Trends Biotechnol. 23:48-55.

46. Prachayasittikul V, Prachayasittikul S, Somsak R, Prachayasittikul V (2009). High therapeutic potential of Spilanthes acmella: A review. EXCLI Journal 12:291-312. - ISSN 1611-2156.

47. Virk PS, Zhu J, Newbury HJ, Bryan GJ, Jackson MT, Ford-Lloyd BV (2000). Effectiveness of different 
classes of molecular marker for classifying and revealing variation in rice (Oryza sativa) germplasm. Euphytica. 112:275-284.

48. Vos $P$, Rogers $R$, Bleeker $M$, Reijans $M$, Van-deLee $T$, Hornes $M$, Fritjers A, Pot J, Peleman J, Kuipe M, Zabeau M (1995). AFLP: A new technique for DNA fingerprinting. Nucleic Acids Res. 23:407-4414.

49. Wang DG, Fan JB, Siao CJ, Berno A, Young P, Sapolsky R, Ghandour G, Perkins N, Winchester E, Spencer J (1998). Large-scale identification, mapping, and genotyping of single-nucleotide polymorphisms in the human genome. Science. 280:1077-1082.

50. Weber May, Abundant class of human DNA polymorphism which can be typed using the polymerase chain reaction. Am. J. Hum. Genet. 44 (1989) 388-396.

51. Welsh J \& McClelland M, Fingerprinting genomes using PCR with arbitrary primers. Nucleic Acids Res. 18 (1990) 7213-7218.

52. Wenzl P, Li H, Carling J, Zhou M, Raman H, Paul E, Hearnden P, Maier C, Xia L, Caig V, Ovesna J, Cakir $M$, Poulsen D, Wang J, Raman R, Smith $K$, Muehlbauer G, Chalmers K, Kleinhofs A, Huttner E, Kilian A (2006). A high-density consensus map of barley linking DArT markers to SSR, RFLP and
STS loci and agricultural traits. BMC Genomics. 7:206. doi: 10.1186/1471-2164-7206.

53. Williams JKF, Kubelik AR, Livak KG, Rafalki JA, Tingey SV (1990). DNA polymorphisms amplified by arbitrary primers are useful as genetic markers. Nucl. Acids Res. 18:6531-6535.

54. Wolff K, Zietkiewicz E, Hofstra H (1995). Identification of chrysanthemum cultivars and stability of DNA fingerprint patterns. Theor. Appl. Genet. 91:439-447.

55. Wu LC, Fan NC, Lin MH, Chu IR, Huang SJ, Hu CY, Han SY (2008). Anti-inflammatory effect of spilanthol from Spilanthes acmella on murine macrophage by down-regulating LPS-induced inflammatory mediators. J. Agric. Food Chem. 56:2341-2349.

56. Zhang L, Zhang HG, Xf L (2013). Analysis of genetic diversity in Larix gmelinii (Pinaceae) with RAPD and ISSR markers. Genet. Mol. Res., 12:196-207. PMID: 23408406.

57. Zietkiewicz E, Rafalski A, Labuda D (1994). Genome fingerprinting by Simple Sequence Repeat (SSR)-anchored polymerase chain reaction amplification. Genomics 20:176-183. DOI:10.1006/geno.1994.1151

*Corresponding Author: Lavanya Devi $K^{*}$

Email: lavanyakotekar@gmail.com 